Sylwia Kulczyk

\author{
THE NATURE OF BOUNDARIES OF GEOCOMPLEXES \\ AND THE LANDSCAPE TYPES: THE EXAMPLE OF THE \\ SURROUNDINGS OF PIŃCZÓW IN SOUTHERN POLAND
}

\title{
INTRODUCTION
}

The study of the landscape boundaries has a history of more than a hundred years and it has become an increasingly popular object of research of both geographers and landscape ecologists (Hansen, Di Castri, 1992; Forman, 1995). Geocomplex — a landscape unit having concretely defined boundaries, remains one of the most often used reference areas in geographical research. It appears necessary, therefore, to precisely identify the nature of boundaries of the units determined.

The basis for the present report was constituted by the materials gathered for purposes of the M.A. thesis entitled "Problems of classification of geocomplex boundaries in various types of landscape on the example of the surroundings of Pińczów", elaborated in the Department of Geoecology under the tutorship of Dr W. Lewandowski. The study was carried out on a relatively small (104 sq. km) area of the uplands of southern Poland. Within its confines three subareas can be distinctly seen, differing as to the landscape type (Richling, 1966). In the western part the loess forms dominate, while in the eastern one - chalk-and-gypsum forms prevail, and the central part is taken by the valley of Nida river - i.e. a river valley landscape.

\section{THE METHOD OF WORK}

The units, whose boundaries were subject to analysis, constituted geocomplexes of undefined taxonomic rank, these units having been determined using the formalised method of leading factors, developed by Richling (1979) for the post-glacial areas, and modified in the Department of Comprehensive Physical Geography of the Faculty of Geography and Regional Studies for the upland areas. When determining geocomplexes the differentiation of three leading components of the environment were accounted for: lithological features, relief, and land use. The maps of geocomplexes, of the 
scale of $1: 10,000$, resulting from field studies, were generalised afterwards to the scale of $1: 25,000$.

The nature of the thus defined landscape boundaries were analysed through the study of four properties: density, sinuosity, contrast, and univocality.

On the basis of the map of geocomplexes the number of boundaries in the fields of the surface of $1 \mathrm{sq}$. $\mathrm{km}$ was measured. The results obtained were classified, and then presented in the form of a cartogram and an isarythmic map.

The sinuosity of the boundaries, understood as the degree of complication of the boundary line, was represented by the fractal dimension. The so called box dimension was used, which, in view of simplicity of calculations, is one of the most often applied in various domains of science (Peitgen, Jürgens, Saupe, 1992). The essence of calculations consists in making the result of measurement of the length of a curve dependent upon the scale in which the measurement takes place. "Boxes" of various dimensions, being in fact pixels of various dimensions $(2,5,10,20,50,100,200,500$ and 1000 metres) were adopted as the measurement scale. Calculations were performed with the Ilwis program, separately for each of the landscape types analysed, considering all boundaries determined within the given area. The dependence of the numbers obtained $(u)$ upon the measure of precision $(s)$ was illustrated on a diagram. In view of the wide range of values the decimal logarithms of the values obtained were used, with the measure of precision being the inverse of the pixel dimension $(1 / s)$. The points determined tend to align along the straight lines. Assuming that the dependence of the measurement result on the dimension of the pixel is governed by a power law, we obtain:

$$
\begin{gathered}
u=c / s^{d} \\
\log u=d \log (1 / s)+\log c
\end{gathered}
$$

where: $1 / s$ is the indicator of measurement precision, $u$ - the result obtained, $\log c$ - the coordinate of intersection with the $O y$ axis, $d-$ directional coefficient of the straight line. The value of $d$ is the fractal dimension we are looking for. It can be read out from the diagram as the angle of the straight line, or calculated by dividing the respective differences appearing on the $O x$ and $O y$ axes.

When determining the contrast of boundaries the method applied by Richling (1974) was taken for the model. Contrast was expressed as the number of features, which are different for the units separated. Hence, all boundaries were classified as weakly contrasted - with just one feature differing, medium contrasted - when two features differed, and strongly contrasted, separating areas differing as to three features. The class of strongly contrasted boundaries was assumed to comprise also the boundaries between land and water areas, as well as those with the strongly anthropogenically transformed areas.

The last of the characteristics analysed was unambiguity of boundaries. 
An unambiguous boundary would correspond to such a landscape contour, which could be traced through field observation. This kind of analysis was not meant to undermine the objective existence of the units determined on the map. The very process of delimitation, though, would indicate that the course of landscape boundaries is often not quite uniquely defined. It appears obvious that the less the boundary is clear in the terrain, the more difficult it is to determine it. In carrying out classification of boundaries with respect to their unambiguity in the field additional factors were also accounted for, namely the number of features which served to determine the boundary, and the natural or artificial character of the boundary. Simple boundaries are the ones which separate areas differing by just one feature (lithology, relief, or land use). When more than one feature was accounted for in determining the boundary, such a boundary was called complex. Classification into natural and artificial boundaries was done on a very simplified principle. These boundary contours were treated as artificial, which can be changed under the influence of human activity during just one season, like, for instance, the boundaries of stone quarries, fishponds, plantations, as well as overbuilt areas.

THE RESULTS OF THE STUDY

\section{DENSITY OF GEOCOMPLEX BOUNDARIES}

The density of boundaries of geocomplexes changes depending upon the type of landscape. The valley landscape is distinguishable through a low number of boundaries per $1 \mathrm{sq} . \mathrm{km} \mathrm{(0-4)}$. The density of boundaries on the loessy area displays strong differentiation. The slopes declining softly towards Nida river, are also characterised by a low density of boundaries (at most 7 boundaries per $1 \mathrm{sq} . \mathrm{km}$ ). The highest density of boundaries (exceeding 32 boundaries per $1 \mathrm{sq} . \mathrm{km}$ ) is observed within the area cut through by a deep lateral valley, constituting the erosion basis of an extensive network of loess gullies.

In case of chalk-and-gypsum landscape the isarythmic map shows that the number of contours attains maximum in the area of a structural gypsum threshold, clearly marked in the landscape. The larger part of the chalk-andgypsum area is characterised by a medium density of boundaries, of a dozen or so boundaries per 1 sq. $\mathrm{km}$.

\section{SINUOSITY OF GEOCOMPLEX BOUNDARIES}

The value of the fractal dimension for boundaries in the loessy landscape is 1.26. This fractal dimension is equal in the river valley landscape to 1.21 , and in the chalk-and-gypsum landscape - to 1.22. The thus low values and 
the essential similarity of the results obtained can be explained by the fact that these are the averages for the whole analysed fragment of the given landscape type. Hence, the ultimate result was a superposition of values describing the sinuosity of boundaries of small units having complex shapes and those for linear boundaries, like the ones delimiting the overbuilt areas.

\section{CONTRAST OF THE BOUNDARIES OF GEOCOMPLEXES}

The boundaries between the valley landscape and the loessy and chalkand-gypsum landscapes are on their almost entire length strongly contrasted. This fact confirms the correctness of distinction of the valley landscape as a separate unit.

Among the boundaries of geocomplexes in the loessy landscape the highest share $(70 \%)$ is taken by the weakly contrasted boundaries; $26 \%$ of all the boundary contours correspond to the middle contrasted boundaries, and $4 \%$ are the strongly contrasted boundaries. The results obtained indicate that the dominating factor shaping the course of the boundaries in the loessy landscape is constituted by relief. This fact seems to be explained by the lithological uniformity of the area, with the simultaneous susceptibility of loess to the relief-forming activity. Relief is largely connected with land use, which is confirmed by the high share of medium contrasted boundaries connected with the change in relief and land use simultaneously.

In the valley landscape the weakly contrasted boundaries constitute $55 \%$, the medium contrasted boundaries - 15\%, and the strongly contrasted ones $-30 \%$ of the totality of boundaries analysed. The data obtained emphasise the morphological homogeneity of the valley landscape. The boundaries appearing in this type of landscape - except for the boundaries delimiting the geocomplexes linked with the persistent presence of water - are linked exclusively with the lithological features of land use.

The highest percentage share in the total number of boundaries in the chalk-and-gypsum landscape is taken by the weakly contrasted boundaries (55\%). The medium contrasted boundaries constitute $29 \%$, and the strongly contrasted ones $-16 \%$ of the whole set of the boundary contours analysed. These values are much like those obtained for the valley landscape. The chalk-and-gypsum landscape, though, is characterised by a much bigger differentiation of the boundary types appearing. The results thus acquired reflect the mosaic-like nature of the chalk-and-gypsum landscape. The differentiation of lithology is connected with the differentiation of the relief forms, which are oftentimes emphasised by the changes in land use. This seems to be the explanation for the high share of medium contrasted boundaries, connected with the change in lithology and relief, and for a high number of strongly contrasted boundaries. 
UNAMBIGUITY OF THE BOUNDARIES OF GEOCOMPLEXES

The boundaries separating the valley, loessy, and chalk-and-gypsum landscapes belong — with a marginal exception - to unambiguous boundaries. This seems to confirm the superior character of these boundaries.

High degree of univocality characterises boundaries determined in the loessy landscape (see Table 2). Of the boundaries classified $67 \%$ were unambiguous. A high share of unambiguous simple boundaries (30\%) must be explained by the existence of numerous distinctly perceived dry valleys, slope pots, and gullies on sharp slopes, clear outlines of the slopes themselves, as well as a high number of boundary contours, delimiting land use shifts. Among the ambiguous boundaries the largest part is constituted by the ambiguous simple boundaries (29\% of the totality of boundaries). Their appearance is connected with ridge flats, soft slopes, and dry valleys which cut through them.

The shares of unambiguous and ambiguous boundaries in the valley landscape are, respectively, $55 \%$ and $45 \%$. Among the unambiguous boundaries the natural unambiguous boundaries dominate $(30 \%)$. The contours of unambiguous natural complex boundaries (20\%) are defined by the reach of the river bed and the over-flood terrace, while the unambiguous natural simple boundaries (10\%) correspond to the reach of the forest complex. Among the ambiguous boundaries only the type of ambiguous natural simple boundaries was identified, corresponding to changes in the bedrock. The above considerations indicate that the univocality of the boundaries in the valley landscape is largely influenced by their degree of complexity. This is expressed through the fact that no ambiguous natural complex boundary was identified.

The chalk-and-gypsum landscape is characterised by an equilibrated appearance of unambiguous (52\%) and ambiguous ( $48 \%$ ) boundaries, with a slight domination of the former. Among the unambiguous boundaries natural ones dominate $(28.5 \%)$, connected first of all with the geocomplexes existing within the area of the gypsum quest. The natural unambiguous complex boundaries dominate in this group (24\%). Among the ambiguous boundaries $30 \%$ are the natural ambiguous simple ones. They are mainly connected with the changes in relief within the area of the little inclined slopes or with bedrock changes, unrelated to the relief changes. The analysis conducted indicates that the univocal boundaries are linked with these fragments of the chalk-and-gypsum landscape, which are characterised by strongly expressed features of relief (gypsum quest). Ambiguous boundaries dominate on the remaining areas.

\section{CONCLUSIONS}

The following conclusions can be drawn on the basis of the results presented above:

1) The differentiation of the types of geocomplex boundaries reflects the differentiation of the landscape types. 
2) The features analysed (density, sinuosity, contrast, unambiguity) do not display, in their majority, mutual relations. The sole observed connection is the fact that the strongly contrasted boundaries are also unambiguous.

3) The highest density of boundaries was noted in the loessy landscape, characterised by the most differentiated relief.

4) In all the analysed types of landscape the boundaries are characterised by a similar degree of sinuosity. The highest sinuosity of boundaries was stated for the loessy landscape. The present author sees a connection between this fact and a high differentiation of the relief forms in the loessy landscape.

5) The most frequent type of boundaries in terms of contrast are in all of the three landscapes the weakly contrasted ones. The highest share of the strongly contrasted boundaries was observed in the valley landscape (namely - the lines separating water and land areas).

6) The highest degree of unambiguity characterises the boundaries of geocomplexes in the loessy landscape. This fact is connected with the existence of numerous differentiated, clear forms of relief.

\section{REFERENCES}

F or m a n R.T.T., 1995, Land Mosaics: the Ecology of Landscapes and Regions, Cambridge University Press, Cambridge.

Hans en A., di Castri F., 1992, Landscape Boundaries, Springer Verlag, New York.

Peitgen H.O., Jürgens H., S a u pe D., 1992, Fractals for the Classroom. Part I: Introduction to Fractals and Chaos, Springer Verlag, New York.

Pi e tr z a k M., 1995, Średnioskalowa mapa krajobrazowa - eksperyment kartograficzny [A middle-scale landscape map - a cartographic experiment], [in:] Studia krajobrazowe jako podstawa racjonalnej gospodarki przestrzennej, Wroclaw.

Richling A., 1966, Typy środowiska abiotycznego [Types of abiotic environment], Prace Geograficzne, 47, IG PAN.

Richling A., 1974, Analiza struktury środowiska geograficznego i nowa metoda regionalizacji fizycznogeograficznej (na przykładzie województwa białostockiego) [Analysis of the structure of geographical environment and a new method of physicogeographical regionalisation (on the example of Bialystok voivodship)]. Typescript.

Richling A., 1979, Z metodyki wydzielania uroczysk w terenach glacjalnych [On the methods of delimitation of ranges in the post-glacial areas], Przeglad Geograficzny, $51(4)$. 